\title{
Como 'si se conversase con los muertos'. La prudencia y su centralidad en la confección de la historia durante el siglo XVII
}

\author{
Aarón GRAGEDA BUSTAMANTE \\ Universidad de Sonora \\ agrageda@sociales.uson.mx
}

\begin{abstract}
RESUMEN
Esta contribución se dedica a analizar el lugar de la prudencia como concepto epistemológico fundamental a principios del siglo XVII en España. En un intento por explicar la influencia y repercusiones impuestas por el culto a la prudencia en la historia, se mostrará la manera en que fueron introducidos lineamientos $y$ puntos de vista metodológicos, por parte de dos historiadores y cortesanos del rey Felipe III; a saber, Antonio de Herrera y Tordesillas y Luis Cabrera de Córdova. Así, se describirá finalmente la base retórica, pragmática y epistemológica de esta concepción de la historia, y desde luego, su supuesta utilidad como herramienta intelectual en la toma de decisiones, tanto del militar como del hombre de Estado.
\end{abstract}

PALABRAS CLAVE: Retórica, Prudencia, Historia, Herrera, Cabrera

\begin{abstract}
This paper addresses the significance of prudence as a fundamental historiographical concept at the beginning of 17 th century in Spain. Making the attempt to explain the influence and repercusions imposed by the cult of prudence in History, I will show in the work of two authors, Antonio de Herrera y Tordesillas and Luis Cabrera de Córdova, both of them historians and courtiers of King Philip III, how methodological outlines and points of view were introduced into the discourse. By doing so, I finally describe the rhetorical, pragmatical and epistemological basis of this particular conception of history and, last but not least, its supposed utility as an intellectual tool for decision making of military and statesmen.
\end{abstract}

KEYWORDS: Rhetorics, Prudence, History, Herrera, Cabrera

"Iam vero non negavirem, ex Historicorum lectione praecipuam collige prudentiam"

Erasmus, Institutio Principis Christiani, 1516.

El año de 1602, el doctor en letras Eugenio Narbona redacta una serie de reflexiones que le servirán meses más tarde para elaborar la presentación de su libro, referente a la historia del rey don Juan el Segundo. En dicho manuscrito consigna las siguientes palabras: "la prudencia, que como dice Platón es la que guía a los hombres al bien obrar, se alcanza por dos caminos; o experiencia o estudio".* Al extenderse en su escrito afirma

\footnotetext{
* A lo largo de esta contribución, y con el fin de uniformizar las diferencias prosódicas expresadas en las diferentes fuentes que se citan, se empleará un criterio de transcripción moderno.
} 
que el primer camino, el camino de la experiencia, es el "mas cierto, pero el mas dificultoso, porque se compra a precio de la vida y no todos se aprovechan de lo que los años y la edad enseñan, siendo en la vejez menos corregidos que en la juventud". El segundo, el de la historia, es por el contrario el camino "mas breve y mas llano y que menos costa acarrea al bien que se pretende, enseñando con ajeno peligro a huir del nuestro, y por esto es más seguido por ser mas los que pretenden con ajenos ejemplos aprender". 1

Este convencimiento lleva al escritor a señalar, que si se considera el tiempo transcurrido del hombre sobre la tierra, es más lo "que la historia enseña que lo que la experiencia advierte". Por eso, recuerda Narbona, "sin la historia el mas envejecido en otras ciencias es niño en el gobierno y consejo". Acerca de las diferentes formas de escribir historia concluye: "no todas de una manera aprovechan, porque aunque todas enseñan, no todas se encaminan a ese fin". Por ejemplo, si bien Tito Livio se "lee mas contento y deleitado, sale con la suavidad y elegancia en decir con los varios y admirables casos que cuenta [...]”, Cornelio Tácito es quien para su gusto “enseña con los sucesos cómo se sube, se conserva y acaban los imperios, qué artes de paz y guerra hacen mayores o declinan a las monarquías, y no con invención como Jenofonte”, remata, "sino con verdad acaecida enseña a formar un acertado gobierno". ${ }^{2}$

Los aspectos que Eugenio Narbona introduce en las anteriores disquisiciones, llegaron a ser lineamientos constitutivos de una tradición historiográfica específica, que otorgó al concepto de prudencia un significado central; la prudencia se cultivó con el auxilio de la historia como doctrina capaz de otorgarle sentido al pasado, lo que permitió en la época, ver en ella una herramienta útil para la orientación del sujeto y su toma de decisiones en contextos inciertos como los que antepone la fortuna en asuntos de Estado.

\footnotetext{
1 Archivo de la Universidad de Salamanca (en adelante "AUS"); Ms. 2168, Contenidos varios, "Prólogo de la historia del Rey D. Juan el Segundo por el doctor Eugenio Narbona, dirigida al Rey D. Felipe III", 1602, f. 102-105. De Eugenio Narbona se ha escrito que "fue natural de la ciudad de Toledo, doctor en sagrados cánones y párroco de la Iglesia de San Cristóbal en la misma ciudad, pronotario apostólico, varón docto, erudito y elocuente. Obtuvo un beneficio en la capilla de San Blas en la Santa Iglesia primada de Toledo, fundada por su arzobispo don Pedro Tenorio, que floreció en tiempos de don Juan I y don Pedro III, reyes de Castilla", véase: N. A. HISPALENSI, Bibliotheca Hispana Nova, t. I, Madrid, Joaquín Ibarra, 1783, art. Eugenius Narbona, p. 361.

2 AUS, Ms. 2168, f. 102.
} 
Este artículo, complementa contribuciones historiográficas previas, que se fundamentan en la tradición clásica. ${ }^{3}$ Utiliza para este fin los apuntes de dos cronistas castellanos del siglo XVII; a saber, Antonio de Herrera y Tordesillas y Luis Cabrera de Córdova. ${ }^{4}$ De esta manera, se describe qué recursos epistemológicos vincularon a la prudencia con la historia, cómo se efectuó con su ayuda la significación del pasado y sobre todo bajo qué lineamientos impuso la prudencia en lo relativo a la forma en que debía narrarse lo sucedido. Los aspectos que se desarrollan a continuación permiten afirmar que por entonces, el conocimiento del pasado comunicado por la historia fue medio de un fin que le fue superior; a saber, educar al individuo en la previsión, particularmente al súbdito, al noble o al cortesano, lo que exigió, no sólo adaptar el concepto renacentista de historia, buscar un lugar de realización en la tradición humanista posterior, sino también introducir procedimientos de indagación y escritura que pudieran hacer posible cultivar tal virtud.

Con los ejemplos que aquí se vierten es posible describir el alto grado de sistematicidad que adquirió la disciplina histórica a principios del siglo XVII; así como comprender su discreta naturaleza retórica, estilística y metodológica. Esto último permitió hacer de la prudencia una doctrina que vio en la historia su fundamento epistemológico. 5

\footnotetext{
${ }^{3}$ Sin poder, por limitantes de espacio, ser comprensivos, destacan aportes que vinculan la teoría de la historia con la prudencia, entre otros los de R. LANDFESTER, Historia Magistra Vitae: Untersuchungen zur Humanistischen Geschichtstheorie des 14. bis 16. Jahrbunderts, Géneve, Droz, 1972; R. KOSELLECK, Futures Past: On the Semantics of Historical Past, Cambridge, Cambridge University Press, 1985 (sobre todo en el capítulo intitulado: "Historia Magistra Vitae: The Dissolution of the Topos into the Perspective of a Modernized Historical Process"); C. GINZBURG, "Pontano, Maquiavelo y la prudencia. Algunas reflexiones mas", Anales de Historia Antigua, Medieval y Moderna, 43 (2001), 115-126; M. B. CASTAÑÓN MORESCHI, "Historia magistra vitae' e imitación: la ejemplaridad política de las historias en Maquiavelo", Ingenium. Revista del pensamiento moderno, 7 (2013), 43-70; J. RÜSEN, Geschichte im Kulturprozess, Cologne, Böhlau, 2002 y A. GRAGEDA BUSTAMANTE, "De prudencia y ocasión. La historia como respuesta a los contrasentidos éticos de la razón moderna", História da Historiografía, 12 (2013), 79-99.

${ }^{4}$ Sobre el contexto intelectual de la época de Antonio de Herrera y Luis Cabrera ver: S. MONTERO DÍAZ, "La doctrina de la historia en los tratadistas españoles del Siglo de Oro", Hispania, 4 (1941), 3-37.

5 Algo que pensadores más contemporáneos, como Arthur C. Danto, omiten al reflexionar sobre las operaciones analíticas de la historia, sobre todo porque no consideran el papel fundamental de la conciencia histórica, capaz de alentar esfuerzos humanos sistemáticos, como el cultivo de la prudencia, para hacer frente a lo ocasional e imprevisto del futuro. En A. C. DANTO, "Prudence, History, Time and Truth", en D. CARR, T.R. FLYNN, R. A. MAKKREEL (eds.), The Ethics of History, Illinois, Northwestern University Press, 2004, p. 85.
} 


\section{La historia, un medio para}

Al comenzar las reflexiones de lo que puede considerarse su aportación historiográfica fundamental, Luis Cabrera de Córdova consigna que "uno de los medios más importantes para alcanzar la prudencia, tan necesaria al Príncipe en el arte de reinar, es el conocimiento de las historias". "Siguiendo a Flavio Vegecio, especialista en el arte de la guerra, ${ }^{7}$ Cabrera afirma que la historia posee un carácter práctico ya que "da noticia de las cosas hechas", de donde "se ordenan las venideras, y así para las consultas son utilísimas".

Esta función práctica le viene a la historia de su naturaleza mnemónica, toda vez que tiene por fin "ayudar, enseñando con la fresca memoria de los hechos, mejor que las estatuas, pinturas, trofeos y otros monumentos”. En esta lógica expresa que la historia es "madre de la prudencia, madre de los buenos efectos". 8 Por ello, de acuerdo con Cabrera, la historia no cumple su función sólo con "escribir las cosas para que no se olviden"; ello no es sino un medio dado a los hombres, como afirma Aristóteles, "para que se enseñen a vivir con la experiencia, maestra muda", algo que pueden emplear "los particulares que perfeccionan la prudencia".9 De ahí que citando a Eneas Silvio Piccolomini, ${ }^{10}$ Cabrera afirme que "el fin de la historia es la utilidad pública".

El entendimiento de la historia como medio (y no sólo como fin de conocimiento válido por sí mismo), es compartido también por Antonio de Herrera y Tordesillas, quien al discurrir sobre la utilidad que su cultivo conlleva establece: "De poco sirven los trabajos de los historiadores sino van encaminados a fin que se pueda conseguir de ellos el principal provecho de su lectura, que es la prudencia, virtud que da siempre a los hombres materia para ejercitarse y forma a la felicidad". ${ }^{11}$

${ }^{6}$ L. CABRERA DE CÓRDOVA, De historia, para entenderla y escribirla, Madrid, Imprenta de Luis Sánchez, f. $1 \mathrm{v}$

${ }^{7}$ F. VEGECIO, De re militari libri quatuor, Paris, Lutetia, 1532. Anotaciones tomadas del libro I, capítulo 9 .

${ }^{8}$ CABRERA, De historia, f. 6v

${ }^{9}$ CABRERA, De historia, f. 19v. Aristóteles, Ética. "Singularum prudentia est, qua notae homini per usum siunt".

${ }^{10}$ E. S. PICCOLOMINI, I commentarii rerum memorabilium, quae temporibus suis contigerunt, Milano, Adelphi Classici, 1984.

11 A. DE HERRERA Y TORDESILLAS, Discursos morales, politicos, e históricos inéditos [...], Madrid, Imprenta de Ruiz, 1804, p. 21. 
Para Herrera, la prudencia se nutre de la historia, es el "arte de antever el fin de las acciones humanas, sin engañarse fácilmente en la elección de los medios que le pueden llevar a ello". Dado que "la vida del hombre es breve espacio para conseguir la perfección de esta virtud, con solo las cosas que él mismo vé y trata", se necesita aprender de la historia y poder de esta forma "adquirir con dificultad esta ciencia de bien vivir tan necesaria en todo tiempo y a todos estados". ${ }^{12} \mathrm{El}$ entendimiento de la prudencia como una ciencia útil "en todo tiempo y a todos estados", significa que en la época, Herrera consideraba a la prudencia como virtud general, a la vez que herramienta propia del hombre, por el solo hecho de ser hombre; es decir, con independencia de su condición o dignidad como sujeto.

Es importante afirmar que en la base epistemológica de este entendimiento pragmático de la historia (donde a ésta se le cultiva como un almacén de casos sucedidos que permiten favorecer la previsión), el ser humano se entiende, en su evidente diversidad, como realización de un solo y mismo Dios, por lo tanto, más allá de los rasgos y circunstancias que lo diferencian, el mundo es en esencia el mismo desde que fue creado; por ello consigna Luis Cabrera de Córdova que "una misma manera de mundo es toda. Las que han sido, vuelven aunque de bajo de diversos nombres, figuras y colores que los sabios conocen, porque las consideran con diligencia y observación". 13

Partiendo de ese presupuesto, Herrera revela en su discurso la manera en que se efectúa la transmisión de la prudencia por medio de la historia; a saber, utilizando en la narración sentencias, ${ }^{14}$ mismas que se subliman como máximas del comportamiento humano y se ofrecen al lector al momento de explicar los hechos pasados: "[...] no veo como la historia puede ser de fruto sin advertimientos y sentencias", expresa, "porque el ejemplo particular no es bastante por sí mismo a enseñar la buena imitación”, por ello, "conviene que leyendo historias, y considerando cada cosa de lo que contienen, vaya el hombre formando en sí mismo una cierta regla general de las acciones particulares, que no es otra cosa sino la prudencia". ${ }^{15}$

\footnotetext{
12 HERRERA, Discursos, p. 23

13 CABRERA, De historia, f. 1v.

${ }^{14} \mathrm{El}$ Diccionario de Autoridades (REAL ACADEMIA ESPAÑOLA, Diccionario de la lengua castellana, en que se explica el verdadero sentido de las voces, su naturaleza y calidad [...], Madrid, Imprenta de la Real Academia Española, 1739, p. 82, col. 1) define como sentencia el "dicho grave o sucinto, que encierra doctrina o moralidad digna de notarse".

15 HERRERA, Discursos, p. 31
} 
En este orden de ideas, Herrera advierte a quien escribe el pasado: "conviene que la historia nos represente cualquier suceso, no simple ni desnudo, sino vestido de sus causas y de todos aquellos accidentes que le acompañan, porque sin la causa de tales particulares no se puede llegar a la universal conclusión, que es el verdadero principio de obrar con razón cierta”. ${ }^{16}$

Precisamente, por su función primaria, constituir un tesoro de enseñanzas probadas por la experiencia y disponibles a cualquiera para aprender a ser previsor, Herrera recuerda que "todos los imperios del mundo, no sólo políticos, entre los cuales se han venerado las ciencias y las artes liberales como a dioses y gobernadores suyos, pero aún los bárbaros, ciegos de razón, han estimado a la historia y profesores de ella". Añade además que esto se hacía “con mucha razón, pues por su antigüedad y por la utilidad y provecho es madre y verdadera luz de las demás ciencias y facultades". ${ }^{17}$ Ese mismo valor social es reconocido por Cabrera, cuando establece que tratándose de historia "la divina enseña religión, la humana prudencia y la natural ciencia, y todas deleitan". 18

Habiendo aclarado así la relación intrínseca que vinculaba el estudio de la historia con la formación intelectual de quien aspiraba a ser tam prudens quam eruditus homo, ${ }^{19}$ es necesario afirmar que la difícil elaboración de las lecciones y sentencias extractadas en los libros de historia exigía, para que abonaran al cultivo de la prudencia, un tipo especial de historiador, ya no el renacentista ni el humanista, sino alguien que también pudiera poner en operación una serie de criterios normativos específicos, al momento de emprender la escritura de lo acontecido. Algunos de los requerimientos definidos en la época son descritos a continuación.

\section{Criterios normativos relevantes en la escritura de la historia}

La enseñanza y la ejemplaridad son las características dominantes de una práctica histórica orientada al fin último, que es adquirir la virtud de la prudencia. Luis Cabrera de Córdova hace mención de ambas cuando afirma que con ellas el historiador mira a lo universal, "pues todo su fin es enseñar universalmente a bien vivir con los ejemplos, con

\footnotetext{
16 Idem.

${ }^{17}$ HERRERA, Discursos, p. 43

18 CABRERA, De historia, f. 18v.

${ }^{19}$ E. GARIN, Prosatori latini del Quattrocento, Milán, Riccardi, 1952, p. 814
} 
las oraciones acomodadas a las personas, tiempos, cosas y casos". Consignando el pasado, el historiador "enseña a decir y hacer, contando la naturaleza de las personas, sus alabanzas, vituperios, y otras partes llenas de doctrina civil". ${ }^{20}$

Junto a las características antes mencionadas, el acto de anticiparse a los hechos encontró un espacio igualmente relevante, sobre todo porque se creía que la historia buscaba, como expresa Cabrera, "prevenir en lo futuro con madura prudencia, argumentando de las cosas del estado presente y del ejemplo de las pasadas lo que sería en lo porvenir". ${ }^{21}$ En torno a la previsión, la historia se considera en la época un fundamento de certidumbre, sobre todo si se observa que, como afirma Herrera, por "la diversidad de los gobiernos, variedad de los tiempos, de las costumbres y de tan diversos accidentes hay necesidad de muy larga experiencia”. La historia hace posible, según este autor, "adquirir una verdadera prudencia para que ningún caso parezca nuevo ni perturbe ningún accidente, sino que se muestre tal que con el conocimiento de los sucesos humanos, haya aprendido a proveer a todas las cosas que haya antevisto". ${ }^{22}$

Ejemplaridad, enseñanza y previsión hacían posible como triada, que una historia alcanzara utilidad práctica y sirviera a la persona para disponerle sin grandes riesgos a aprovechar la ocasión y sortear los cambios de fortuna. Por ejemplo, si aprende de historias forjadas con dicha fragua, supone Antonio de Herrera que en una embestida "el defensor de una plaza sabría dilatar la cura (como dicen) y acomodarse al tiempo conociendo el estado de su enemigo, que es la parte de la prudencia, que es mas conveniente y necesaria para un capitán general”. 23 “Como la prudencia es principio de toda buena operación", advierte, "así se puede decir que es la historia casi un principio de donde deriva la misma prudencia". ${ }^{24}$

\subsection{Es verdadera y posee fundamento en la experiencia}

Si bien los lineamientos de redacción de la historia siguieron estando normados en la época por una tradición predominantemente humanista; es decir, de corte retórico, centrado en textos clásicos y para la educación del hombre de Estado, existió en este

\footnotetext{
${ }^{20}$ CABRERA, De historia, f. 12v.

${ }^{21}$ Ibid., f. 175v.

22 HERRERA, Discursos, p. 25

${ }^{23}$ Ibid., p. 84

${ }^{24}$ Ibid., p. 25
} 
entendimiento de la historia una parte dedicada estrictamente a la selección cuidadosa del material y de la información a emplear. Tratándose de historia, su contenido, para ser útil a este fin, debía provenir estrictamente de la experiencia.

En sus discursos, Antonio de Herrera y Tordesillas recuerda que "la experiencia en todas las cosas humanas es gran fundamento, porque es guía del entendimiento, que regula y modera la voluntad, es el ánima de la prudencia, sin la cual no hay buen gobierno en la paz ni en la guerra". Bajo ese convencimiento, afirma que sin experiencia no se puede pretender "conocer las enfermedades de un estado, ni aplicarle los remedios en su lugar y tiempo, ni conocer las calidades ni conveniencias". ${ }^{25}$

El tratamiento sistemático que Herrera busca establecer respecto al pasado, lo lleva a expresar que "los mas sabios juzgan que la experiencia es de dos maneras: la una, la que habiendo procedido del tiempo, ha enseñado reglas en aquella forma que padece el continuo movimiento de las cosas humanas; la otra", añade, "es la que hace el hombre particular en el curso de su edad". La primera experiencia es histórica, en tanto que la segunda es biográfica. "La experiencia que hace prudentes a los príncipes y ministros ha de ser compuesta de las dos cosas referidas", ${ }^{26}$ advierte.

Por consiguiente, Herrera sostiene que "es verdaderamente sabio el hombre en el cual se unirán y juntarán las dos referidas experiencias, como fueron", añade citando ejemplos clásicos, "aquellos dos ojos de Grecia, luces perpetuas del gobierno civil Licurgo y Solón, que formaron las dos famosas repúblicas que florecieron por espacio de ochenta años, los cuales”, concluye, “tuvieron tanta lumbre y juicio para templar sus leyes de tal manera que hasta hoy se gobierna gran parte del mundo con ellas". ${ }^{27}$

Al tener fundamento en la experiencia, la práctica de la escritura del pasado adquiere sus elementos propios y definitorios. Luis Cabrera de Córdova consigna: "Yo digo, es la historia narración de verdades por hombre sabio, para enseñar a bien vivir". 28 Una narración verdadera supone además tomar de lo acaecido la información asequible al presente y que sea fehaciente, surgiendo de ahí la necesidad de utilizar criterios de idoneidad en el empleo de las fuentes. Por ejemplo, tratándose de testimonios de terceros, Cabrera afirma su seguridad de que debe utilizarse la información de aquellos

\footnotetext{
${ }^{25}$ Ibid., p. 91

${ }^{26}$ Ibid., p. 92

${ }^{27}$ Ibid., p. 93

${ }^{28}$ CABRERA, De historia, f. 11v.
} 
quienes intervinieron en las expediciones, como ministros, y se hallaron presentes a los hechos, ya que por su cargo se les ha de dar más crédito.

Llámense relaciones, antiguallas o memoriales, Cabrera de Córdova recuerda que al escribir historia "la materia no la inventa el historiador, ni la escoge entre otras el escritor que sirve a su príncipe, sino que se la dan y él pone prudencia y elocuencia para decir, teniendo poder sobre la misma, como quien toma la piedra para pulirla y darle conveniente forma con ingenio y arte". ${ }^{29}$ Para asegurar una perspectiva imparcial y comprensiva, no basta para el historiador "la confirmación de los autores auténticos", sino que debe valerse "lo más probable de los escritos de otros"; debe corroborar en todo momento "la armonía de los tiempos, lugares, sitios, personas, nombres, armas, mármoles, trofeos, estatuas, sepulcros, inscripciones, monedas, empresas, blasones, etimologías, privilegios y tradiciones". ${ }^{30}$ Respecto a las fuentes, su calidad y origen advierte: "Los que pretenden escribir los corrientes de los tiempos no se deben fiar de lo que oyen, ni de particulares opiniones de escritores, sino de aquellos de quien depende la fe pública de los hechos, como son los anales de los archivos reales", ya que es ahí donde los ejemplos historiados se hallan indagados con mayor certeza.

\subsection{Es útil en la medida que logra ser imparcial}

En torno a las condiciones y limitantes de quien escribe, señala Herrera que "[...] hará bien el oficio de historiador quien escriba con ánimo libre”. Esto lo consigue el historiador al "pintar las cosas como acontecieron; lo cual no podrá hacer si teme o tiene esperanza de premio, o tiene odio contra alguno, estimando por muy necesario lo que conviene al bien público, haciendo más caso de la verdad que de la enemistad". Por lo tanto, es propio del oficio de historiador el que se tenga que "sacrificar a la sola verdad con modestia, y en suma es medida cierta el no mirar a los presentes, sino a los que adelante han de revolver las historias". 31

La imparcialidad como lineamiento historiográfico, es una característica de la escritura de la historia, casi tan antigua como el surgimiento de la disciplina. Sin embargo, en la historiografía del siglo XVII, ésta renueva en el cultivo de la prudencia su

\footnotetext{
${ }^{29}$ Ibid., f. $27 \mathrm{v}$.

30 Ibid., f. 32r.

${ }^{31}$ HERRERA, Discursos, p. 12
} 
significado: la imparcialidad se labra, no sólo para lograr la neutralidad requerida para formar juicio acerca de los actos humanos descritos, sino que sin ella, el frágil proyecto de extraer del pasado las enseñanzas políticas y las sentencias requeridas para alimentar la prudencia fracasa.

En el sentido anteriormente expresado, el Cronista Mayor de Indias refiere, "atento a lo que dice Tucídides", que "se debe aplicar el histórico a escribir con tal ánimo y opinión, que su voz y su declaración sea vehemente y continua, y su exordio sosegado y quieto; las sentencias acompañadas y frecuentes, el estilo llano y civil, que con gran significación manifieste lo que trata". Por ello, "si conocemos que la prudencia aumenta tanto sus fuerzas en las acciones particulares con la lección de la historia”, reitera Herrera, "cuanto mayor provecho se pueda esperar que se seguirá de ellas para el bien regir la República". 32

En ese mismo tenor, Luis Cabrera de Córdova recuerda que lo contrario a la imparcialidad; vicios como la adulación, el elogio o incluso el odio a los enemigos, hacen que germinen en el escritor las perturbaciones, que sólo arriban para "impedir el juicio recto y no ver lo que conviene, y lo que es honesto, por más que guarde la igualdad y la neutralidad". ${ }^{33}$ Para evitar que la prudencia se extravíe en el camino de una historia marcada por la afectación, sugiere que el que escribe sea libre siempre de admiración, conmiseración, ambición, adulación, para no afectar la narración. Recuerda que en el cultivo de la prudencia "las figuras y las sentencias son piedras preciosas, de que ha de estar la oración guarnecida, no vestida". ${ }^{34}$

\subsection{Es llana su prosa porque el ornamento distrae la sentencia}

En su ensayo sobre la suficiencia de la historia como medio para alcanzar la prudencia, Antonio de Herrera afirma que "no cumplen los buenos historiadores con la simple narración, sino que deben mezclar e instruir en ella muchas sentencias para que el lector pueda con facilidad aprender aquellos preceptos que son el verdadero fruto de la historia, porque de otra manera", declara, "más servirá la historia para deleite que para aprovechar". Quienes lean historias que deleitan pero que no educan sobre como

\footnotetext{
32 Ibid., p. 25

33 CABRERA, De historia, f. 47v.

34 Ibid., f. $94 \mathrm{v}$.
} 
anticipar los actos humanos, "ninguna utilidad conseguirán para si mismos, ni para la República". 35

Al referirse a la historia como medio para llegar a ser prudente, cuya función es extraer del pasado (y transmitir al presente) las máximas del comportamiento humano, Antonio de Herrera consigna: "la historia declara las cosas realmente sucedidas, y también el provecho que de ella se sigue, porque la doctrina que adquirimos con la experiencia de las cosas singulares nos cuesta muy cara y con muchos peligros; pero que la lección de la historia contiene en sí la doctrina sin alguna incomodidad”. ${ }^{36}$

Por ello es categórico en sostener: “[...] no veo como la historia pueda ser de fruto sin advertimientos y sentencias, porque el ejemplo particular no es bastante por sí mismo a enseñar la buena imitación, antes podría ser ocasión de que se hiciesen muchos yerros". Es imperativo por lo tanto escribir una historia "que no abundase de vanas digresiones fuera del propósito principal, ni que tampoco fuese desnuda de las cosas necesarias, siguiendo en todo el ornamento y el estilo liso y apacible". "Si una historia lleva un lenguaje confuso y oscuro, y una traza revuelta y turbada con digresiones y discursos largos y prolijos, omitiendo cosas que le tocan, no veo como se puedan sacar de ella los bienes que se pretenden, especialmente", señala, "el de la prudencia". 37

La historia tiene un género, argumenta por su parte Luis Cabrera de Córdova, en éste "se cuenta adornada, y realmente la verdad en los sucesos varios y contiene oraciones, más su estilo es liso y corriente, porque su intento ni es deleitar, ni persuadir”. Esto último lo logra, "cuando enseña con la variedad de los sucesos, consejos y modos de ejecutarlos, y con las mudanzas increíbles de la fortuna". ${ }^{38}$

Es por esa razón que sugiere al historiador o cronista que "trabaje las oraciones bien, con estilo liso, grave, más lleno de buenas razones y sentencias que de colores y figuras de retórico". Desde esta lógica, la historia que logra ser "breve y cauta es la mejor", agrega, ya que teniendo "cerca la conclusión de la proposición, se percibe y conserva mejor en la memoria".39 Cabrera recomienda entonces que "para que la narración no sea plebeya no diga adagios, sentencias si, como matrona ilustre de cuando

\footnotetext{
35 HERRERA, Discursos, p. 26

36 Ibid., p. 10

${ }^{37}$ Ibid., p. 32

38 CABRERA, De historia, f. 183v.

39 Ibid., f. $169 \mathrm{v}$.
} 
en cuando, útiles para la gravedad, docilidad, apretar, impeler, amonestar, perfeccionar en las personas y cosas grandes, con decoro y autoridad". ${ }^{40}$

Tomando en cuenta los elementos antes señalados, coincidiendo con Cabrera, Antonio de Herrera advierte con un dejo de desprecio, que tratándose de historia, "los que con solo el fin del ornamento de las palabras la escriben, merecen justamente el nombre de sofistas". 41 Cabe señalar finalmente que en su conjunto, los criterios normativos antes descritos, amplios como son, perfilaron según ambos autores un tipo particular de historiador, con actitudes, atributos y habilidades susceptibles de contribuir desde la escritura de la historia al cultivo y enseñanza de la prudencia.

\section{Cualidades del historiador y de su estilo}

En el ensayo de Antonio de Herrera, la prudencia tiene una definición, "es semejante al arte y a la música", es "guía de la virtud, maestra de los efectos, hija de la razón, virtud intelectual y dada al hombre para su defensa". Agrega sin embargo, que "para formar enteramente esta joya tan preciosa se requiere conciliar tres cosas": primeramente "la memoria de las cosas pasadas", en segundo lugar "el conocimiento de las presentes" y finalmente "echar de ver las venideras; en lo cual muestra especialmente la prudencia su fuerza y en ella da su verdadero fruto". 42

Partiendo de ese entendimiento, sostiene que "tal se requiere que sea el historiador, que nada atribuya al odio ni a la enemistad, no perdonando, no teniendo compasión, sin empacho ni respetos, siendo igual juez y tan apacible con todos, cuanto lo pide el no atribuir a nadie cosa contra razón”. Historiadores que aspiren a escribir de esta manera, deberán ser de “ingenio más despierto y de madura prudencia en el juzgar". Para Herrera no hay duda respecto a que historiadores con esos atributos, "aguzando su ingenio escogerán lo mejor y desecharán lo contrario", con lo que "la candidez del escritor resplandece y se conoce con ella la verdad de la historia", sobre todo cuando "se ve que contiene los tiempos, el sitio de los lugares, el modo del gobierno, el número de

${ }^{40}$ CABRERA, De bistoria, f. 170r.

${ }^{41}$ HERRERA, Discursos, p. 46. Según S. DE COVARRUBIAS (Tesoro de la lengua castellana o española, Madrid, Luis Sánchez, 1611, p. 1266, 2a columna.), "este nombre fue antiguamente honesto y bueno, vale tanto como sabio, de la palabra griega sophia, que vale sapientia", pero después cambió para denotar a "algunos arrogantes y habladores, que parecían saber mucho y eran charlatanes".

${ }^{42}$ HERRERA, Discursos, p. 22 
los que pelean en los ejércitos y de los que van a las empresas, allende de los hechos que se cuentan". 43

En cuanto a la forma de escribir, advierte al historiador que "es bueno cierto viento poético que hinche las velas con aliento próspero, y lleve levantada la nao por lo alto por medio de las altas ondas, y con todo eso", subraya, "la manera de hablar vaya llana, con hermosura y grandeza de las cosas que se cuentan, sin mostrarse peregrino ni fuera de tiempo, porque esto sería vicioso y pesado a los oyentes". ${ }^{44}$

Luis Cabrera de Córdova es más extenso que Herrera al momento de describir los atributos del historiador interesado en hacer de su escritura fundamento de prudencia. Señala que éste "ha de saber buenas letras, tener lección de las divinas, ser docto en las antigüedades, práctico en el mundo, y que haya peregrinado”. A su vez, deberá ser alguien "ejercitado en todas materias, principalmente de Estado, inteligente en las cosas de la guerra, hombre áulico, versado en los negocios públicos, y gobiernos de los reinos, provincias, pueblos", lo mismo que "inquiridor de los hechos ocultos, lleno de sentencias y dichos graves, instruido en ejemplos, elocuente, grave, entero, severo, urbano, diligente, medido, estudioso, de gran seso, bondad y justicia”. ${ }^{45}$ Con esa actitud, disciplina y habilidad se garantizará que sea "un varón realmente bueno, para que no dé ni quite mas de lo que conforme a razón toca a cada uno, ejercitado en el escribir con entera salud, ingenio acomodado, e inclinado de lo alto para historiar, hacienda con qué vivir, que ni espere ni tema". ${ }^{46}$

Sobre la calidad que deberá poseer el historiador orientado al cultivo de la prudencia, Cabrera de Córdova afirma que éste deberá ser "elegante, con estilo limpio, corriente, alto, trabajado con diligencia, perfecto por arte, uniforme, igual en el contexto del principio, medio y fin". Junto a lo anterior agrega que éste no sea "en nada afectado", tenga "sana y buena gramática"; así como cuidado "en el poner y ordenar las palabras, para que no la haga difícil”. Señala finalmente, que este estilo será más lacónico que breve, elocuente pero natural, claro, con lo que conseguirá que "sea suave y grave la narración". 47

\footnotetext{
${ }^{43}$ HERRERA, Discursos, p. 7

${ }^{44}$ Ibid., p. 14

${ }^{45}$ CABRERA, De historia, f. $15 \mathrm{r}$.

46 Idem.

${ }^{47}$ CABRERA, De historia, f. $187 \mathrm{v}$.
} 


\section{Pintura, historia y prudencia}

La relación entre historia y prudencia puede comprenderse en los dos autores aquí analizados, si se observa por último en sus escritos, que para representarles estrechamente unidas, ambos recurrieron a la estrategia de considerarlas tan cercanas la una a la otra, como lo está la imagen de lo que representa.

Luis Cabrera de Córdova afirmó que a la historia la "pintan doncella gentil con alas, porque aunque es memoria de cosas consecutivas, dignas de saberse, va por todo el mundo pura y cándida, sin falsedad en el decir, por miedo, amor ni interés; esto significa", el porque posa "sobre un mármol cuadrado, asiento del que juzga, lleno de yerbas siemprevivas, como ella es, y como por ella son las personas y las cosas". ${ }^{48} \mathrm{Se}$ suma a la descripción de la pintura de la historia, que "mira atrás mostrando ser de lo pasado, nacida para la posteridad con lo que escribe en un libro que tiene en la siniestra”. "Saturno le entrega la verdad que saca de una nube", afirma, "con título de hija del tiempo, de que la historia es testimonio". "Desnuda", agrega, "porque la simplicidad le es natural, con el sol en la diestra en alto, que mira por ser luz ella y amiga de la luz, con un ramo de palma, porque vence y el pie sobre el mundo que ha de saber". ${ }^{49}$

Herrera tampoco ahorra colores y matices en su boceto: "por la estimación en que fue siempre tenida la historia, pintaban los antiguos a Jano, Dios de la prudencia, con dos caras, porque mirando en las historias lo pasado, se acierta prudentemente en lo porvenir". De esta suerte, inspirado en Cicerón, menciona que con la historia "parece que hemos vivido en los siglos antepasados, porque nos pone delante de los ojos los ilustres ejemplos de la divina sabiduría, gobernadora de los imperios, representando”, afirma, "las ruinas que se siguieron de los hechos injustos, y los premios de los que fueron justos". Este carácter de la historia y la enseñanza que brinda "instituye la vida civil y edifica la espiritual, aumenta la sabiduría y adorna la elocuencia, inflama el ánimo a la virtud y le aparta de vicios, inmortaliza a los virtuosos y sepulta a los malos, enriquece de fama a los sabios y no hace caso de los ignorantes". 50

\footnotetext{
${ }^{48}$ Ibid., p. 5 v.

${ }^{49} \mathrm{Idem}$

${ }^{50}$ HERRERA, Discursos, p. 49
} 
Para concluir, cabe señalar, que en los textos históricos leídos por los súbditos castellanos en la época, se afirmaba una y otra vez esta relación entre historia y prudencia; entre conocimiento histórico y conocimiento práctico: "la historia para composición de la vida deber ser estimada por utilísima, lo uno porque a los mozos iguala con los viejos en prudencia; lo segundo a los viejos y de madura edad, a los cuales la vida alarga". "Sola la historia", consigna por entonces Diódoro en sus escritos, "representando las cosas acaecidas, abraza y contiene dentro de sí toda utilidad, porque a seguir lo honesto pone espuelas, abomina los vicios, a los buenos ensalza, abate a los malos y finalmente con la experiencia de las cosas que relata, mucho provecho trae para la vida virtuosa y recta". ${ }^{51}$

\section{A manera de conclusiones}

Tomando en consideración los elementos antes expuestos, fundamentados en las afirmaciones elaboradas por los dos autores de principios del siglo XVII aquí analizados, pueden establecerse algunos lineamientos constitutivos de la práctica de escritura histórica que hizo de la prudencia su interés central y que la cultivó como una ciencia de Estado. ${ }^{52}$

Primeramente, el conocimiento histórico elaborado de acuerdo a este modelo epistemológico se debe entender vinculado con la formación del hombre político y encargado de la administración del gobierno real; era dirigido a sujetos relacionados con los asuntos de la guerra y la conducción monárquica. En este contexto, semejante a lo afirmado por Melanchthon, puede entenderse la práctica de la historia como civilium negotiorum ratio. ${ }^{53}$

Esta historiografía es producto de un papel espiritual y político activo por parte del individuo, surge del interés y cuidado de los clásicos, al tiempo que se aparta de una significación histórica sacra y teleológica del mundo (como sucedió durante la Edad

51 Citado en J. PÉREZ DE TUDELA y E. LÓPEZ OTO, Obras escogidas de Bartolomé de Las Casas, Madrid, Imprenta y estereotipia de M. Rivadeneyra, 1957, p. 579.

${ }^{52}$ Cfr. G. FONTANA ELBOJ ("El Genio de la historia de Fray Jerónimo de San José en el marco de la tratadística histórica del Humanismo", Alazet 14 (2002), p. 145) es alguien quien por el contrario, ha descrito la historiografía española en los siglos XVI y XVII caracterizada por: a) un proceso de secularización, con el correspondiente abandono del providencialismo y los hechos milagrosos; b) el predominio de historias bajo patrocinio, con carácter apologético y propagandístico; c) con interés propagandístico, y d) rindiendo culto a la forma literaria latina y tendiente a mover sentimentalmente al lector.

53 P. MELANCHTON, Philippi Melanchthonis sermo habitus apud juventutem academiae Wittemberg. De corrigendis adulescentiae studiis, Johan Grunenberg, Wittemberg, 1518. 
Media). Lo anterior afirma su impronta historiográfica renacentista. Ahora bien, así considerada, la práctica de la historia como medio para alcanzar la prudencia, reconoce un carácter que se aproxima a los lineamientos historiográficos del Humanismo, ${ }^{54}$ particularmente porque: 1) se concibe como herramienta del hombre (sobre todo del noble o del cortesano), útil para anticipar los actos humanos; 2) tiende a posibilitar la ampliación del conocimiento del pasado por su dimensión empírica, al tiempo que se pensaba como filosofía enseñada con ejemplos; 3) subraya la utilidad práctica del conocimiento histórico, al considerarla un medio, más que un fin en sí mismo; y 4) permitió finalmente instruir y aprender las reglas para ser virtuoso y prudente con el programa del "Studia Humanitatis".

Se deduce de las afirmaciones de Antonio de Herrera y Luis Cabrera, que esta modalidad historiográfica, si bien se respaldó en contribuciones clásicas como las de Platón, Aristóteles, Quintiliano, Cicerón y Diódoro, consiguió nutrirse de autores más contemporáneos como Robortelo, Pontano, y Lipsius, de quienes adoptó lineamientos de composición histórica surgidos en el horizonte de los siglos XVI y XVII. Introdujo así, con especial interés, esquemas críticos de manejo de información, reconstrucción y representación del pasado, lo cual hace evidente la aparición, por lo menos en ciernes, de una dimensión lógico-racional inédita.

Intentó mostrarse en los apartados precedentes, que la historia escrita para adquirir la prudencia tuvo como lineamientos para la configuración del pasado, el manejo de la verdad fundamentada en la experiencia, reutilizó para su causa la premisa historiográfica de la imparcialidad, impuso un estilo llano y sentencioso en la escritura, así como propuso que la historia fuera elaborada por una persona elocuente, erudita, conocedora de las artes retóricas así como de la gramática; a la vez que, por un individuo y súbdito intachablemente honesto, de buen y probado ingenio. En ello se consiguió un espacio y utilidad específica en el concierto de la historiografía de la época.

Se esperaba con la conjunción de los anteriores lineamientos y atributos, dar vida a una escritura de la historia que alcanzara en doble partida la ejemplificación moralpedagógica (enseñar aquellas cosas que debían hacerse), a la par que a conseguir un

\footnotetext{
${ }^{54}$ P. BURKE ("The spread of Italian Humanism", en A. GOODMAN y A. MACKAY (eds.), The Impact of Humanism in Western Europe, Routledge, Londres, 1990, p. 2), define el Humanismo como "el movimiento dedicado a recuperar, interpretar y asimilar el lenguaje, la literatura, la enseñanza y los valores de la Grecia y Roma antigua".
} 
conocimiento práctico-empírico (el conocer mejor los acontecimientos humanos del pasado). Las instrucciones relativas al manejo del material histórico y su transformación en narración, contaron en correspondencia con un lado material y otro estilístico. Por último, en esta concepción de la historia, la verdad de lo narrado fue tan relevante como su capacidad para ser utilizado por parte del sujeto lector de historia, para alimentar su capacidad de anticiparse al porvenir. Por lo tanto, más que por su poder de esclarecimiento del pasado y por salvar la memoria del olvido, su eficiencia radicaba en lo futuro, en el arte y virtud de poder prever. De ahí que la historia así entendida era considerada para la vida como "utilísima". La historia cultivada como medio para alcanzar la prudencia fue expresión del espíritu renacentista, maduró en el repertorio intelectual del Humanismo donde encontró seguidores y ensayistas cortesanos que le dedicaron extensas páginas, como Antonio de Herrera y Luis Cabrera de Córdova en el siglo XVII.

Mucho antes que Eugenio Narbona, escritores como Pero Mexía de Guzmán, Cronista Real de Carlos V, mencionaban ya a mediados del siglo XVI el uso de la historia como herramienta de previsión. Éste último recordaba por ejemplo al príncipe Felipe II, décadas antes de que Herrera y Córdova publicaran sus ensayos, que "el buen emperador Alejandro Severo, cada vez que había de tratar y deliberar de grandes negocios y hechos de guerra, principalmente llamaba y consultaba sobre ellos a los varones leídos y sabios en las historias antiguas". ${ }^{55} \mathrm{Al}$ respecto, Mexía expresaba que "Zenón, príncipe de los estóicos filosofos, siendo preguntado cómo se podría el hombre hacer bienaventurado y sabio, respondió que si conversase con los muertos, que es tanto", concluía, "como si dijera, si leyere y supiere las historias y los hechos de los antiguos". ${ }^{56}$

Resta señalar, que con el presente aporte se establece simultáneamente una agenda más ambiciosa de investigación, que se aboque como en el caso Mexía de Guzmán, a evaluar los antecedentes inmediatos de esta concepción particular de la historia, para elaborar con ello su diferenciación respecto a las demás prácticas historiográficas de la época. Queda pendiente aún realizar una indagación comprensiva de las influencias intelectuales que esta forma de utilizar el conocimiento histórico tuvo en el horizonte

\footnotetext{
${ }^{55}$ P. MEXÍA DE GUZMÁN, Historia imperial y cesárea: en la que en suma se contiene las vidas y hechos de todos los césares emperadores de Roma: de Julio César hasta el emperador Maximiliano: dirigida al muy poderoso príncipe y señor nuestro don Philippe, principe de las dos Sicilias, Sevilla, Casa de Juan de León, 1545, f. iiii ${ }^{56} \mathrm{Idem}$.
} 
cultural moderno, tanto en España como en el mundo iberoamericano. Lograr con esta contribución su síntesis como manifestación intelectual específica ha sido tan sólo un pequeño paso en esa dirección. 